\title{
A study of changes in axial length of eye during accommodation in Indian population
}

\author{
Deshpande S. ${ }^{1}$, Gala Y. ${ }^{2}$ \\ Dr. Shrikant Deshpande, Associate Professor, MGM Medical College, Navi Mumbai. ${ }^{2}$ Dr. Yash Gala, Junior Resident, \\ MGM Medical College, Navi Mumbai, Maharashtra, India.
}

Corresponding Authors: Dr. Shrikant Deshpande, Associate Professor, MGM Medical College, Navi Mumbai, India. Email: shrieyecare@gmail.com

\begin{abstract}
Purpose: We performed this study to measure the changes of axial length during accommodation and see whether refractive error has any influence in effect of changes during accommodation. Method: This study included 75 subjects who were divided into three groups according to refractive status. Axial length was measured before and after accommodation with A-scan. Accommodation was achieved by asking the subject to focus on N/6 line of near vision chart held at a distance of $33 \mathrm{~cm}$ with left eye with full refractive correction on the left eye. Results: The mean increase in axial length was $0.051,0.004$, and $0.005 \mathrm{~mm}$ in Groups A, B and C respectively when focus of the left eye was shifted from $6 \mathrm{~m}$ to $33 \mathrm{~cm}$. On further increasing the accommodation by shifting the focus of the left eye to $12.5 \mathrm{~cm}$, the axial length increased by 0.08, 0.07, and $0.007 \mathrm{~mm}$ in Groups A, B, and C respectively. There was no significant difference in between three groups in these changes. Conclusions: There was tiny but statistically significant increase in axial length along with accommodation in this study. This may be indirectly linked to the causation of myopia. There was no variation with refractive error in these changes.
\end{abstract}

Keywords: Axial length, Accommodation, A-scan

\section{Introduction}

Accommodation is a unique mechanism by which we can focus the diverging rays coming from a near object on the retina to see clearly. This is achieved by changing thickness of lens by action of ciliary muscles and zonules upon it. Various methods like slit-lamp photography, optical pachymetry, A-scan ultrasonography, and partial coherence inferometry (IOL master) have been used to observe the changes in ocular structures during accommodation.

Studies carried out on this subject have yielded different and inconclusive results. Mallen et al reported greater change in axial length in myopes as compared with emmetropes [1]. Ocular changes during accommodation may differ with refractive status of the eye. Epidemiologic studies have found a correlation between excess near work and myopia. The axial length changes during accommodation due to excess near work may influence the onset of myopia. This may give a possible explanation of increased incidence of myopia in recent

Manuscript received: $5^{\text {th }}$ July 2018

Reviewed: $15^{\text {th }}$ July 2018

Author Corrected: $20^{\text {th }}$ July 2018

Accepted for Publication: 24 $4^{\text {th }}$ July 2018 times due to excess near work such as studying and using gadgets. No study has been carried out to compare the difference of changes during accommodation in Indian population. This study was carried out to measure the changes of axial length and other parameters during accommodation and see whether refractive error has any influence in effect of changes during accommodation in Indian population.

\section{Material and Methods}

This study was carried out in a tertiary care hospital in India. Seventy-five subjects were included in this study after written and informed consent. The subjects were divided in three groups according to refractive status. Group A consisted of 25 emmetropes. Group B consisted of 25 myopes with myopia <5 D while Group $\mathrm{C}$ consisted of 25 hypermetropes with hypermetropia $<5 \mathrm{D}$.

Exclusion criteria: Patients having following were excluded from the study:

1. Age less than 18 year or more than 30 years. 
2. Convergence insufficiency

3. Amblyopia

4. Strabismus

5. Other diseases affecting visual acuity e.g. any media opacity, corneal surface irregularities, uveitis, macular diseases

6. Best corrected visual acuity $<6 / 6$

7. Myopia $>5 \mathrm{D}$; hypermetropia $>5 \mathrm{D}$

8. Intraocular pressure $>24 \mathrm{~mm} \mathrm{Hg}$

Preliminary examination included keratometry, measurement of intraocular pressure, slit lamp examination and fundus examination.

The refractive error was determined by retinoscopy carried out one and half hour after instillation of one drop of $1 \%$ cyclopentolate for three times at the interval of ten minutes.

Subjects were made to sit upright. Fisher et al showed that monocularly and bimocularly induced accommodative effect are similar in magnitude [2]. Hence, the left eye was used for fixation and right eye was used for biometric studies.

Biomedix Echorule A- scan ultra sonography machine with a frequency of $10 \mathrm{MHz}$ and contact probe was used in this study. Biometry was performed in phakic mode with gain setting of $70 \%$.

Right eye was anaesthetized using topical $0.1 \%$ proparacaine eye drops. The subject was asked to focus on 6/6 line of Snellen's chart kept at a distance of 6 meters with full refractive correction on the left eye.

Lids of the right eye were gently separated with fingers without applying any pressure on the globe. A-scan probe tip was gently put on the center of cornea with its direction along the visual axis perpendicular to cornea. Before proceeding further it was ensured that the subject has sharp image of 6/6 line of Snellen's chart with left eye. The echo-spikes were observed for height of echoes indicating amplitude and sharpness.

Readings were taken by freezing the A-scan by pressing the foot-pedal. Readings were taken only when following condition were fulfilled which indicated that the probe was aligned along the visual axis:

1. Tall and sharp echoes from cornea, anterior lens surface, posterior lens surface and vitreo-retinal surface.

2. The retinal echoes should be steeply rising without any steps, humps or jags.

3. Presence of scleral echoes

Similar procedure was repeated after accommodation. Accommodation was achieved by asking the subject to focus on N/6 line of near vision chart [Roman test type] held at a distance of $33 \mathrm{~cm}$ with left eye with full refractive correction on the left eye. It was ensured that the subjects had clear and sharp image of letters on N/6 line. Biometry was performed on the right eye simultaneously and readings of anterior chamber depth, lens thickness and axial length were taken.

Then, the subjects were asked to focus N/6 line of near vision chart held at $12.5 \mathrm{~cm}$ to increase the amplitude of accommodation and similar procedure was repeated.

The accommodation was relaxed by adding $+3 \mathrm{D}$ to the refractive correction on the left eye. The subjects were then asked to focus at N/6 line of near vision chart held at $33 \mathrm{~cm}$ with left eye. Biometric procedures were done on the right eye.

Statistical analysis of the above readings was carried out by using paired and unpaired ' $\mathrm{t}$ ' tests.

\section{Results}

There was no significant difference in treatment groups with respect to age and sex distribution. Group B consisted of myopes with mean refractive error of $-1.93+1.39$ in right eye and $-2.03+1.09$ in left eye. The mean refractive error of group $\mathrm{C}$ was $+1.9+1.28$ in right eye and $+1.69+1.21$ in left eye. Group A comprised of emmetropes.

An increase in axial length with accommodation was noted in all three groups. The mean increase in axial length of Group A was $0.051 \mathrm{~mm}$ when focus of the left eye was shifted from $6 \mathrm{~m}$ to $33 \mathrm{~cm}$. On further increasing the accommodation by shifting the focus of the left eye to $12.5 \mathrm{~cm}$, the axial length increased by $0.088 \mathrm{~mm}$.

Similar results were obtained in Groups B and C. The increase in axial length during accommodation was found be statistically significant in all three groups with paired ' $\mathrm{t}$ ' test. 
Table-1: Changes in axial length during accommodation.

\begin{tabular}{|c|c|c|c|c|}
\hline S. No & Axial length $[\mathbf{m m}]$ & Group A & Group B & Group C \\
\hline 1. & Focus at $6 \mathrm{~m}$ & $22.96+0.62$ & $24.14+0.79$ & $22.00+0.94$ \\
\hline 2. & Focus at 33cm & $23.01+0.63^{*}$ & $24.19+0.80^{*}$ & $22.04+0.93^{*}$ \\
\hline 3. & Focus at $12.5 \mathrm{~cm}$ & $23.04+0.64^{*}$ & $24.21+0.81^{*}$ & $22.07+0.91^{*}$ \\
\hline 4. & Focus at 33cm With +3 D & $22.96+0.62$ & $24.14+0.79$ & $22.00+0.94$ \\
\hline
\end{tabular}

*statistically significant $(\mathrm{p}<0.05)$

Table-2: Changes in anterior chamber depth during accommodation.

\begin{tabular}{|c|c|c|c|c|}
\hline S. No & $\begin{array}{c}\text { Anterior chamber depth } \\
{[\mathbf{m m}]}\end{array}$ & Group A & Group B & Group C \\
\hline 1. & Focus at 6m & $3.32+0.30$ & $3.45+0.26$ & $3.00+0.24$ \\
\hline 2. & Focus at 33cm & $3.23+0.29^{*}$ & $3.35+0.27^{*}$ & $2.90+0.22^{*}$ \\
\hline 3. & Focus at $12.5 \mathrm{~cm}$ & $3.20+0.31^{*}$ & $3.33+0.29^{*}$ & $2.87+0.21^{*}$ \\
\hline 4. & Focus at 33cm With +3 D & $3.31+0.30$ & $3.44+0.27$ & $2.99+0.23$ \\
\hline
\end{tabular}

*statistically significant $(\mathrm{p}<0.05)$

Table-3: Changes in lens thickness during accommodation.

\begin{tabular}{|c|c|c|c|c|}
\hline S. No & Lens thickness & Group A & Group B & Group C \\
\hline 1. & Focus at 6m & $3.88+0.22$ & $3.92+0.23$ & $4.00+0.20$ \\
\hline 2. & Focus at 33cm & $3.98+0.24^{*}$ & $4.00+0.22^{*}$ & $4.10+0.19^{*}$ \\
\hline 3. & Focus at $12.5 \mathrm{~cm}$ & $4.03+0.25^{*}$ & $4.04+0.22^{*}$ & $4.13+0.20^{*}$ \\
\hline 4. & Focus at 33cm With +3 D & $3.89+0.23$ & $3.92+0.23$ & $4.01+0.19$ \\
\hline
\end{tabular}

*statistically significant $(\mathrm{p}<0.05)$

There was significant decrease in anterior chamber length and increase in lens thickness during accommodation.

The mean change in axial length on shifting focus of left eye from $6 \mathrm{~m}$ to $33 \mathrm{~cm}$ was compared in between groups A, B and C. With the help of unpaired 't' test, 'p' value of $>0.1$ was obtained when group A with group C and group B with group $\mathrm{C}$. Thus, the difference of change in axial length on accommodation in between groups A, B and C was statistically insignificant. Similarly, change in anterior chamber depth and lens thickness was compared in between groups A, B and $\mathrm{C}$ with the help of unpaired ' $\mathrm{t}$ ' test and $\mathrm{p}$ value of $>0.1$ was obtained in all comparisons.

\section{Discussion}

There was tiny but significant increase in axial length with accommodation in 54 out of 75 subjects; while it deceased in 20 subjects and remained unchanged in 1 subject. The mean increase in the axial length on shifting the focus of the left eye from $6 \mathrm{~m}$ to $33 \mathrm{~cm}$ was $0.051,0.052$ and $0.047 \mathrm{~mm}$ in group $\mathrm{A}, \mathrm{B}$ and $\mathrm{C}$ respectively. On shifting the focus to $12.5 \mathrm{~cm}$, the axial length increased by $0.088,0.077$ and $0.077 \mathrm{~mm}$ in group $\mathrm{A}, \mathrm{B}$ and $\mathrm{C}$ respectively. Although the changes in axial length with accommodation were subtle; they were statistically significant as found out by paired ' $t$ ' tests.
Previous studies on this subject have noted similar results i.e. increase in axial length during accommodation. Read et al have reported an increase in axial length during accommodation [3]. Story et al reported mean increase of $0.08 \mathrm{~mm}$ with $2 \mathrm{D}$ of accommodation stimulus in their study carried on 14 subjects carried out with increased with accommodation in most of the subjects. The mean increase in axial length on accommodation was $0.05 \mathrm{~mm}$ when the focus shifted from $6 \mathrm{~m} 33 \mathrm{~cm}$ [4]. Studies using partial coherence interferometry have also reported an increased in axial length during accommodation [5]. 
Decrease in anterior chamber depth with accommodation was noted in this study in 66 out of 75 subjects. Garner et al also reported decrease in anterior chamber depth with accommodation in their studies done with Ascan ultrasonography [6]. Calmettes et al found reduction in anterior chamber depth ranging between 0.1 to $0.5 \mathrm{~mm}$ with a mean of $0.23 \mathrm{~mm}$ with accommodation in their study using optical pachymetry [7]. The decrease in anterior chamber depth during accommodation may due to forward movement of the anterior surface of the lens and an increase in anterioposterior diameter of the lens during accommodation as reported by Kalzuny [8].

There was significant increase in lens thickness with accommodation in 60 out of 75 subjects in this study. Studies using A-scan ultrasonography, slit-lamp photography and partial coherence interferometry have also reported increase in lens thickness with accommodation. Fincham suggested that the lens attains more spherical shape during accommodation due to the elasticity of the lens capsule which causes increase in its thickness during accommodation.

The increase in axial length during accommodation can be explained by Coleman's unified model of accommodation in which he attributed an active role to vitreous chamber. He hypothesized that a pressure gradient between the compressed vitreous and the anterior chamber may occur during accommodation, which may exert stress on the sclera [9].

Shum et al proposal that accommodation might induce an increase in vitreous pressure, which may cause the vitreous chamber to expand and the sclera; which is an elastic to stretch. They further proposed that as the posterior pole is the most extensible pert of the sclera, accommodation causes it to be stretched thereby increasing the axial length.

During accommodation, the change in the lens may not be sufficient to focus the image exactly on the retina. A small backward movement of the posterior pole may strengthen the accommodative effect. The near object may then from a clear image on the retina [10].

In support to Shum's hypothesis, Tokoro et al found that the sclera distended in a longitudinal direction at the equator and in both latitudinal and longitudinal direction at the posterior pole with increasing pole with increasing vitreous pressure [11]. Excess near work is linked with myopia in various population-based studies [12]. Continuous use of accommodation during near work may lead to permanent increase in axial length and may lead to myopia. This study did not find any significant relationship between the accommodation changes in interior chamber depth, lens thickness and axial length with refractive error of the eye.

Limitations of this study include small sample size and use of contact probe for ultrasonography. Studies using immersion method or partial coherence inferometry on large number of subjects may shed further light on this subject.

\section{Conclusions}

This study reported a small but consistent increase in axial length during accommodation with A-scan ultrasonography. This may be responsible for myopia due to excess near work.

The findings of this study correlate positively with the finding of epidemiologic studies which link myopia with excess near work. Excessive use of gadgets such as smart phones, video games, consoles, and tablets may cause myopia. It is recommended that use of these gadgets must be restricted as it may lead to onset and increase in myopia.

The uniqueness of this study was that it studied whether pre-existing refractive error had any influence on axial length changes during accommodation. This study did not find significant correlation in refractive status and ocular changes during accommodation.

Funding: Nil, Conflict of interest: Nil

Permission from IRB: Yes

\section{References}

1. Mallen EA, Kashyap P, Hampson KM. Transient Axial Length Change during the Accommodation Response in Young Adults. Invest Ophthalmol Vis Sci 2006; 47 (3): 1251-4.

2. Fisher RF. Is the vitreous necessary of accommodation in man? Br J Ophthalmol 1983;67 (3): 206.

3. Read SA, Collins MJ, Iskander DR. Diurnal variation of axial length, intraocular pressure, and anterior eye biometrics. Invest Ophthalmol Vis Sci 2008; 49 (7): 2911-8.

4. Storey JK, Rabie FP. Ultrasonic measurement of transverse lens diameter during accommodation. Ophthalmic Physiol Opt 1985;5(2):145-8. 
5. Drexler W, Baumgartner A, Findl O, Hitzenberger CK, Fercher AF. Biometric investigation of changes in the anterior eye segment during accommodation. Vision Res 1997;37(19): 2789-800.

6. Garner LF, Yap MK. Changes in ocular dimensions and refraction with accommodation. Ophthalmic Physiol Opt 1997; 17(1):12-7.

7. Calmettes, Deodati, Huron, Bechac. Study of the depth of the anterior chamber-physiological variations with particular emphasis on ametropia. Am J Optom Arch Am Acad Optom 1966; 43(12):765-94.

8. Kaluzny BJ. Anterior movement of the crystalline lens in the process of accommodation in children. Eur $\mathbf{J}$ Ophthalmol 2007; 17(4): 515-20.
9. Coleman DJ. Unified model for accommodative mechanism. Am J Ophthamol 1970; 69(6):1063-79.

10. Shum PJT, Ko LS, Ng CL, Lin SL. A biometric study of ocular changes during accommodation. Am J Ophthalmol 1993; 115(1): 76-81.

11. Tokoro T. Developmental mecanism of low myopia and therapeutic possibilities. A review. Nihon Ganka Gakkai Zasshi. 1998; 102(12):796-812.

12. Ip JM, Saw SM, Rose KA, Morgan IG, Kifley A, Wang JJ, Mitchell P. Role of near work in myopia: findings in a sample of Australian school children. Invest Ophthalmol Vis Sci 2008; 49(7): 2903-10.

\section{How to cite this article?}

Deshpande S, Gala Y. A study of changes in axial length of eye during accommodation in Indian population. Trop J Ophthalmol Otolaryngol.2018;3(3):8-12.doi:10.17511/jooo.2018.i03.01 